RESEARCH ARTICLE

\title{
In vitro propagation of Coscinium fenestratum (Gaertn.) Colebr. (Menispermaceae) - an endangered medicinal plant
}

\author{
W.T.P.S.K. Senarath* \\ Department of Botany, Faculty of Applied Science, University of Sri Jayewardenepura, Gangodawila, Nugegoda.
}

\begin{abstract}
Coscinium fenestratum (Gaertn.) Colebr. is an important medicinal plant belonging to the family Menispermaceae. Multiple shoots were formed from epicotyl explants on Murashige and Skoog (MS) medium supplemented with $1.0 \mu \mathrm{M}$ kinetin $(\mathrm{Kin})$ and $0.25 \mu \mathrm{M}$ 2,4-Dichlorophenoxy acetic acid (2,4-D). A maximum of five shoots were obtained from one explant in a 75-day culture period. The effect of subsequent subcultures on shoot formation was also studied. Repeated subculture favoured the increase in shoot length and the number of shoots per explant in the media containing Kin and 2,4-D. Higher concentrations of either cytokinin used: butyric acid (BA) or Kin causes stunting of multiple shoots with small and narrow leaves. After $100 \%$ in vitro rooting was obtained in half-strength MS supplemented with $2.5 \mu \mathrm{M}$ Indole-3-butyric acid (IBA), plantlets were transferred to ex vitro conditions. Following a 15-day in vitro rooting period and 12 days of ex vitro acclimatization, $66.7 \%$ of the plantlets were established in the compost beds for another two months to improve the leaf size and then transferred to the field with $100 \%$ survival rate. This protocol has the potential for use as a tool for mass scale production of planting material.
\end{abstract}

Keywords: Conservation, Coscinium fenestratum, Menispermaceae, micropropagation.

\section{INTRODUCTION}

Coscinium fenestratum (Gaertn.) Colebr is a woody climber (popularly known as "weniwel" in Sinhala) which grows wild in the natural rain forest reserves in Sri Lanka and India. This species is listed as endangered in the IUCN Red Data Book and in the Convention on International Trade in Endangered species of wild Fauna and Flora (CITES) listing because of its large scale harvesting for medicinal use ${ }^{1}$. Due to the importance as a medicinal plant, it has become one of the most exploited species. Therefore, sustainable management of this species is needed. In nature, the species propagates through seeds and vegetative perennial stem cuttings. There are records on in vitro callus induction for determination of berberine content in C. fenestratum ${ }^{2}$. However, successful in vitro propagation protocols for the species have not yet been reported. Vegetative propagation is very slow and conventional propagation through seeds and vegetative cuttings is not adequate to meet the demands of conservation and sustainable utilization. Therefore, the development of an in vitro protocol for production of planting material is important to conserve this valuable endangered species. The objective of this study was to develop a feasible in vitro protocol for mass propagation of $C$. fenestratum and acclimatize and establish the planting material in home gardens and their natural habitats.

\section{METHODS AND MATERIALS}

a) Plant material, surface sterilization and explant isolation: $C$. fenestratum seeds were collected from wild populations of the Sinharaja rain forest and the Yagirala conservation forest. They were air-dried and stored in brown paper bags until the experiments were initiated.

Prior to use, seeds were washed with a $2 \%(\mathrm{v} / \mathrm{v})$ tween 20 (mild detergent) solution for $10 \mathrm{~min}$, followed by 2 successive washings in sterile distilled water. Thereafter, the seeds were surface-sterilized for $10 \mathrm{~min}$ in $10 \%$ Clorox $^{\mathrm{TM}}$ (Sodium hypochlorite $\mathrm{v} / \mathrm{v}$ ) followed by thorough rinsing with sterile distilled water. Seeds were clipped and germinated under aseptic conditions on Murashige and skoog $\left(\mathrm{MS}^{3}\right)$ basal medium supplemented with 3\% sucrose and $0.8 \%$ agar. Epicotyl segments from 20-day-old in vitro-germinated seedlings were used as explants. 
Shoot tips were removed from 6-month-old seedlings to induce axillary bud elongation. Axillary buds of $2.0 \mathrm{~cm}$ in length were excised. These were then sterilized by an initial exposure for $10 \mathrm{~min}$ in $10 \%$ Clorox $^{\mathrm{TM}}$ solution and then in $70 \%$ ethanol for $30 \mathrm{~s}$, each followed by 2 successive washings in sterile distilled water.

b) Shoot formation and multiplication: Explants from both in vitro and ex vitro raised seedlings were cultured on MS basal medium solidified with $0.8 \%(\mathrm{w} / \mathrm{v})$ agar. A single explant was placed in each culture tube containing $15 \mathrm{~mL}$ medium supplemented with different concentrations of either butyric acid (BA) or kinetin (Kin) $(0.5,1.0,2.0$ and $4.0 \mu \mathrm{M})$ in combination with 2,4dichlorophenoxy acetic acid (2,4-D) at concentrations of $0.0,0.25$ or $0.50 \mu \mathrm{M}$. Growth regulator free MS medium was used as the control.

At the initial stage, the explants were cultured individually for 30 days. Thereafter, the clumps of shoots produced were divided into single shoots and then periodically sub-cultured at 5 wk-intervals ( 3 times) in the same media type to obtain high multiplication rates.

c) Rooting: Rooting of shoots (after third subculture) was carried out on full or half-strength MS medium supplemented with different concentrations of Indole3-butyric acid (IBA) $(0.0,1.0,2.5$ or $5.0 \mu \mathrm{M})$ and compared with the control (growth regulator free MS medium). All cultures were incubated at $25 \pm 1{ }^{\circ} \mathrm{C}$ under a $16 \mathrm{~h}$ photoperiod with light provided by cool fluorescent tubes at an intensity of 3000 lx.
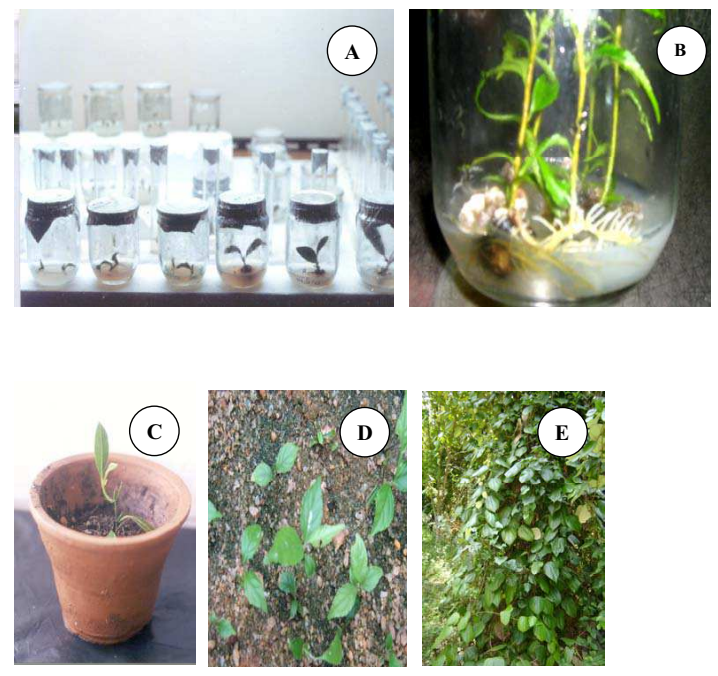

Figure 1A-E: In vitro propagation of Coscinium fenestratum. A) different stages in shoot induction, B) multiplication (leaves become narrow), C) acclimatized plantlets, D) plants grown in compost bed, E) fully grown 8-yearold-plant. d) Transfer of in vitro propagated plants to soil: In order to determine the optimum rooting period and to obtain optimum plantlet output, rooted shoots were removed from the rooting medium (half-strength MS supplemented with $2.5 \mu \mathrm{M}$ IBA) at different time intervals $(0,15,30$ days after rooting). Three replicates of 6 plantlets (a total of 18 plantlets per sampling period) were removed from the culture flasks and washed thoroughly in running tap water to remove all traces of agar attached to the roots. They were then transplanted in plastic pots containing a mixture of autoclaved compost: sand $(1: 1 \mathrm{v} / \mathrm{v})$. Pots were covered with polythene bags to maintain high humidity. Plants were irrigated at weekly intervals with $50 \mathrm{MS}$ in the first week, 25\% MS in the second week and thereafter with tap water.

Plantlets were kept in a growth room. After 12 days, the pots were transferred to a net house for a further period of 2 weeks and irrigated with tap water on alternate days. Polythene covers were removed gradually, and the plants were then transferred to earthen pots containing garden soil. Growth of the plantlets was monitored after transplantation.

e) Statistical analysis: All experiments were carried out using completely randomized design (CRD) and repeated at least 3 times. Unless otherwise stated, 20 explants were used in each treatment. The effect of different treatments was quantified, and the level of significance was determined by the analysis of variance (ANOVA) and least significance difference ( $\mathrm{LSD}<0.05$ ) among mean values ${ }^{4}$.

\section{RESULTS}

\section{Surface sterilization}

Surface sterilization of seeds was successfully achieved with a 10 minute exposure to $10 \%$ Clorox (Sodium hypochlorite) followed by thorough rinsing with sterile distilled water. Almost $100 \%$ of the aseptic seeds germinated within 4 weeks in growth regulator free MS medium.

\section{Shoot initiation and multiplication}

All explants from in vitro germinated seedlings produced shoots on MS medium. The effect of different combinations of culture media on establishment and growth is shown in Table 1. The explants grown on growth regulator free MS medium (control) initiated shoot growth but did not elongate or multiply. However, shoot elongation and multiplication was observed in all 
cultures supplemented with plant growth regulators. The analysis of variance revealed a significant effect $(p<0.05)$ of cytokinin type, concentration and their interactions with 2,4-D on shoot number and length.

The effect of the presence of BA and Kin (cytokinin types) in the MS medium was examined during this phase of propagation. Kin was less favourable for shoot multiplication than BA. With a progressive increase in Kin concentration from $0.5 \mu \mathrm{M}$ to $2.0 \mu \mathrm{M}$ there was a steady decrease in shoot length $(4.3 \pm 0.2-2.0 \pm 0.1 \mathrm{~cm})$. On the other hand, a gradual increase in BA concentration from $0.5 \mu \mathrm{M}$ to $2.0 \mu \mathrm{M}$ significantly increased the shoot number $(1.6 \pm 0.1-3.2 \pm 0.3$ per explant). However, the increase in shoot length was very low $(2.8 \pm 0.1-$ $2.9 \pm 0.1 \mathrm{~cm})$. Higher concentrations of both cytokinins induced shoot multiplication in subsequent subculture cycles but the leaves became narrow (Figure 1A, B).
Addition of 2,4-D at low concentrations $(0.05 \mu \mathrm{M})$ or either Kin or BA (cytokinins) did not produce any significant improvement in shoot multiplication. Combinations of BA with 2,4-D were the least effective for shoot multiplication. Among all the concentrations tested, the best response $(5.0 \pm 0.4$ shoots per explant; $6.0 \pm 0.6$ $\mathrm{cm}$ mean shoot length) was achieved in the presence of $1.0 \mu \mathrm{M}$ Kin and $0.25 \mu \mathrm{M} 2,4-\mathrm{D}$ at the second subculture. Repeated subculture thus favoured shoot length and number for most of the Kin and 2,4-D combinations, whereas for the BA and 2,4-D combinations, it appeared to be effective only at $1.0 \mu \mathrm{M}$ BA.

In the present study, higher concentrations of either cytokinin: BA or Kin $(4.0 \mu \mathrm{M})$ irrespective of the corresponding $2,4-\mathrm{D}$ concentrations $(0.25$ or $0.50 \mu \mathrm{M})$ produced clumps of highly stunted multiple shoots with small and narrow leaves. This reduction in shoot number

Table 1: Effect of different combinations of plant growth regulators and progressive subcultures on the number and length of shoots in shoot cultures of $C$. fenestratum after 45 days following transfer of the shoots to MS medium after each subculture

\begin{tabular}{|c|c|c|c|c|c|c|c|c|}
\hline \multicolumn{3}{|c|}{$\begin{array}{l}\text { Plant growth } \\
\text { regulators }(\mu \mathrm{M})\end{array}$} & \multicolumn{2}{|c|}{ Shoot induction } & \multicolumn{2}{|c|}{ Subculture 1} & \multicolumn{2}{|c|}{ Subculture 2} \\
\hline Kin & BA & $2,4-\mathrm{D}$ & $\begin{array}{c}\text { Mean } \\
\text { no. of shoots }\end{array}$ & Length (cm) & $\begin{array}{c}\text { Mean no. of } \\
\text { shoots }\end{array}$ & Length (cm) & $\begin{array}{l}\text { Mean no } \\
\text { of shoots }\end{array}$ & Length $(\mathrm{cm})$ \\
\hline- & - & - & $0.3 \pm 0.1$ & $0.4 \pm 0.1$ & $0.0 \pm 0.0$ & $0.0 \pm 0.0$ & $0.0 \pm 0.0$ & $0.0 \pm 0.0$ \\
\hline 0.5 & - & - & $1.4 \pm 0.1$ & $4.3 \pm 0.2$ & $4.4 \pm 0.2$ & $2.7 \pm 0.1$ & $1.8 \pm 0.1$ & $2.6 \pm 0.1$ \\
\hline 0.5 & - & 0.25 & $1.2 \pm 0.3$ & $3.8 \pm 0.3$ & $2.1 \pm 0.1$ & $4.7 \pm 0.1$ & $2.0 \pm 0.2$ & $3.7 \pm 0.2$ \\
\hline 0.5 & - & 0.50 & $1.1 \pm 0.2$ & $3.4 \pm 0.3$ & $1.8 \pm 0.1$ & $3.5 \pm 0.2$ & $2.2 \pm 0.1$ & $3.8 \pm 0.4$ \\
\hline 1.0 & - & - & $1.3 \pm 0.1$ & $4.0 \pm 0.2$ & $1.6 \pm 0.2$ & $3.3 \pm 0.1$ & $3.1 \pm 0.2$ & $3.3 \pm 0.4$ \\
\hline 1.0 & - & 0.25 & $1.6 \pm 0.2$ & $4.6 \pm 0.1$ & $2.2 \pm 0.4$ & $4.8 \pm 0.4$ & $5.0 \pm 0.4$ & $6.0 \pm 0.6$ \\
\hline 1.0 & - & 0.50 & $2.2 \pm 0.1$ & $5.2 \pm 0.2$ & $3.4 \pm 0.2$ & $4.9 \pm 0.1$ & $2.3 \pm 0.2$ & $4.1 \pm 0.1$ \\
\hline 2.0 & - & - & $1.5 \pm 0.3$ & $2.0 \pm 0.1$ & $2.1 \pm 0.1$ & $2.1 \pm 0.2$ & $2.7 \pm 0.1$ & $2.3 \pm 0.3$ \\
\hline 2.0 & - & 0.25 & $3.1 \pm 0.1$ & $3.2 \pm 0.1$ & $3.3 \pm 0.2$ & $3.6 \pm 0.1$ & $3.6 \pm 0.4$ & $3.0 \pm 0.1$ \\
\hline 2.0 & - & 0.50 & $1.7 \pm 0.3$ & $4.4 \pm 0.2$ & $1.8 \pm 0.1$ & $3.7 \pm 0.4$ & $2.1 \pm 0.1$ & $4.0 \pm 0.2$ \\
\hline 4.0 & - & - & $1.2 \pm 0.1$ & $1.4 \pm 0.1$ & $1.0 \pm 0.2$ & $3.9 \pm 0.2$ & $0.0 \pm 0.0$ & $0.0 \pm 0.0$ \\
\hline 4.0 & - & 0.25 & $1.0 \pm 0.1$ & $1.4 \pm 0.3$ & $1.2 \pm 0.3$ & $1.7 \pm 0.2$ & $1.7 \pm 0.1$ & $2.3 \pm 0.1$ \\
\hline 4.0 & - & 0.50 & $0.6 \pm 0.1$ & $1.2 \pm 0.2$ & $1.5 \pm 0.2$ & $1.3 \pm 0.1$ & $0.0 \pm 0.0$ & $0.0 \pm 0.0$ \\
\hline- & 0.5 & - & $1.6 \pm 0.1$ & $2.8 \pm 0.1$ & $2.0 \pm 0.2$ & $3.9 \pm 0.2$ & $1.9 \pm 0.1$ & $2.8 \pm 0.2$ \\
\hline - & 0.5 & 0.25 & $2.0 \pm 0.1$ & $4.2 \pm 0.1$ & $1.8 \pm 0.1$ & $4.6 \pm 0.4$ & $2.5 \pm 0.2$ & $4.8 \pm 0.4$ \\
\hline- & 0.5 & 0.50 & $2.1 \pm 0.2$ & $3.9 \pm 0.2$ & $2.0 \pm 0.2$ & $4.0 \pm 0.1$ & $2.6 \pm 0.4$ & $3.2 \pm 0.2$ \\
\hline- & 1.0 & - & $2.4 \pm 0.1$ & $3.9 \pm 0.4$ & $2.7 \pm 0.1$ & $4.1 \pm 0.1$ & $1.8 \pm 0.1$ & $4.3 \pm 0.1$ \\
\hline- & 1.0 & 0.25 & $3.5 \pm 0.2$ & $3.9 \pm 0.2$ & $2.2 \pm 0.1$ & $4.4 \pm 0.4$ & $1.6 \pm 0.1$ & $5.3 \pm 0.4$ \\
\hline- & 1.0 & 0.50 & $1.8 \pm 0.3$ & $2.4 \pm 0.1$ & $2.0 \pm 0.2$ & $4.0 \pm 0.1$ & $1.7 \pm 0.2$ & $3.9 \pm 0.1$ \\
\hline - & 2.0 & - & $3.2 \pm 0.3$ & $2.9 \pm 0.1$ & $3.2 \pm 0.3$ & $2.7 \pm 0.2$ & $3.8 \pm 0.4$ & $3.6 \pm 0.1$ \\
\hline- & 2.0 & 0.25 & $4.0 \pm 0.2$ & $2.3 \pm 0.3$ & $3.3 \pm 0.2$ & $4.0 \pm 0.1$ & $2.9 \pm 0.1$ & $4.2 \pm 0.4$ \\
\hline - & 2.0 & 0.50 & $3.1 \pm 0.1$ & $2.7 \pm 0.1$ & $1.7 \pm 0.1$ & $1.3 \pm 0.2$ & $2.3 \pm 0.2$ & $2.7 \pm 0.1$ \\
\hline- & 4.0 & - & $1.1 \pm 0.1$ & $1.2 \pm 0.2$ & $1.6 \pm 0.3$ & $1.3 \pm 0.1$ & $0.0 \pm 0.0$ & $0.0 \pm 0.0$ \\
\hline- & 4.0 & 0.25 & $0.7 \pm 0.3$ & $1.0 \pm 0.3$ & $2.1 \pm 0.3$ & $1.4 \pm 0.1$ & $1.0 \pm 0.3$ & $1.1 \pm 0.1$ \\
\hline- & 4.0 & 0.50 & $0.6 \pm 0.2$ & $1.2 \pm 0.1$ & $1.3 \pm 0.3$ & $1.3 \pm 0.3$ & $1.0 \pm 0.1$ & $1.5 \pm 0.1$ \\
\hline $5 \% \mathrm{I}$ & & & 0.81 & 1.30 & 1.01 & 1.42 & 1.02 & 1.13 \\
\hline
\end{tabular}

$\mathrm{n}=20$ 
and length was significant $(\mathrm{p}<0.05)$ when compared to the best responding combinations.

\section{Rooting}

The effect of different IBA levels on root induction is summarized in Table 2. Roots were induced in all tested media. In most of the treatments, root initiation was observed after the $3^{\text {rd }}$ week of transferring the shoots to the rooting medium. It was observed that the rooting percentage not only depends on the concentration of IBA but also on the strength of the basal medium. Rooting percentage (highest 66.7\%) was significantly lower in full-strength MS than in half-strength medium (lowest $73.3 \%$ ), and also the rooting process was slower in full strength MS.

Less number of smaller roots were induced in growth-regulator free media. In full-strength MS medium only $20 \%$ of the shoots produced roots while $80 \%$ of the shoots grown in half-strength media induced roots. Addition of $1.0 \mu \mathrm{M}$ or $2.5 \mu \mathrm{M}$ IBA to full-strength MS did not produce any significant effect. Rooting percentage in the presence of 5.0 $\mu \mathrm{M}$ IBA was significantly higher than other IBA concentrations. Conversely, 100\% rooting was achieved in half-strength MS medium supplemented with $2.5 \mu \mathrm{M}$ IBA. Further increase of IBA level into $5.0 \mu \mathrm{M}$ decreased the rooting percentage. Significantly higher number of roots per shoot $(21.6 \pm 0.4)$ and length of the roots $(4.6 \pm 0.3 \mathrm{~cm})$ were achieved in half-strength MS medium supplemented with $1.0 \mu \mathrm{M}$ IBA suggesting that half-strength MS supplemented with either $1.0 \mu \mathrm{M}$ or $2.5 \mu \mathrm{M}$ IBA can be used as standard media type for maximum rooting.

Rooted plantlets were transferred into pots with compost and sand and maintained for 12 days after which they were established in compost beds for a period of 2 months to improve the leaf size. They were then transferred to natural habitats (Figure $1 \mathrm{C}-\mathrm{E}$ ).

\section{DISCUSSION}

Tissue culture as a means for large-scale production of planting material has been reported ${ }^{5-9}$. A replicable and complete micropropagation protocol for Coscinium fenestratum using seedling explants has been developed. Using the micropropagation procedure reported it is estimated that a single explant can produce approximately 20 hardened plants in a complete cycle. This protocol is, therefore, capable of producing well-rooted plantlets of the species.
Wilting or browning of the mature explant makes its use difficult for tissue culture work. In order to save time and cost, juvenile explants were preferred. Ex vitro-raised seedling explants expressed a high degree of fungal and bacterial contamination. Such heavy infections have also been reported in some other medicinal plants and are often related either to the sanitary state of the parent plant or the presence of some dormant bacterial spores resistant to most disinfectants ${ }^{9}$. In such cases, the use of a stronger disinfectant could damage the juvenile tissues of the explant and thus is not very safe to use $\mathrm{e}^{10}$.

Significant improvement in shoot formation over the control has been achieved with the addition of cytokinins like $\mathrm{BA}$ and $\mathrm{Kin}^{11-12}$. BA alone favoured shoot multiplication, which was very obvious as it is considered to be one of the most useful cytokinins for achieving the multiplication and micro-propagation of plants $^{13}$. In the present investigation, a combination of 2,4-D with Kin gave the best response. A reduction in shoot number with increasing cytokinin concentration has been reported in Gymnema sylvestre - an important medicinal plant ${ }^{14}$. A combination of 2,4-D, BAP and Kin (2.0, 2.0, $1.0 \mu \mathrm{M}$ respectively) in MS medium enhances the callus production in C. fenestratum ${ }^{2}$. Thus, the use of a comparatively lower concentration of growth regulator in the present protocol is an important factor to consider, as it minimizes the risk of producing genetically altered individuals. Rooting of in vitro produced shoots was best on half-strength MS medium supplemented with IBA, which has also been reported for some other medicinal plants ${ }^{9}$.

The success of a protocol is assessed largely on the survival and growth performance of propagated plantlets ex vitro. In the present study, results indicate that a 12 day acclimatization period under controlled conditions is required before the plantlets can be transferred to the field. In the beginning, the plants expressed transplantation shock, which can be a result of physiological changes due to severe alterations in environmental conditions and less adapted epidermis of leaves. These in vitro-raised plantlets did not show any apparent morphological abnormality but exhibited improved leaf shape. The tissue cultured plants grown in the field (now 8 years old) did not show any deformations. However, it is importent to compare the chemical constituents of tissue-cultured plants with natural plants after the tissue cultured plants reach maturity.

This protocol provides a successful and rapid technique that can be used for ex-situ propagation and conservation of Coscinium fenestratum (Gaertn.) Colebr. As part of domestication strategy, these plants can be grown and cultivated in fields. The application of this protocol to 
Table 2: The effect of various MS salt concentrations and IBA treatments on root induction in shoots of C. fenestratum after 8 weeks in rooting medium

\begin{tabular}{lcccr}
\hline Basal Medium & IBA $(\mu \mathrm{M})$ & $\begin{array}{l}\text { Rooting } \\
\text { percentage }\end{array}$ & $\begin{array}{l}\text { Mean number of } \\
\text { roots per shoot }\end{array}$ & Mean root length $(\mathrm{cm})$ \\
\hline \multirow{2}{*}{ MS } & 0.0 & 20.0 & $1.3 \pm 0.2$ & $0.55 \pm 0.1$ \\
& 1.0 & 53.3 & $1.6 \pm 0.1$ & $1.1 \pm 0.1$ \\
& 2.5 & 55.3 & $8.9 \pm 0.4$ & $1.8 \pm 0.2$ \\
$50 \%$ MS & 5.0 & 64.7 & $2.7 \pm 0.1$ & $2.1 \pm 0.2$ \\
& 0.0 & 81.0 & $17.2 \pm 0.2$ & $3.9 \pm 0.1$ \\
& 1.0 & 88.7 & $21.6 \pm 0.4$ & $4.4 \pm 0.3$ \\
& 2.5 & 100.0 & $14.2 \pm 0.3$ & $1.8 \pm 0.1$ \\
LSD 5\% & 5.0 & 73.3 & $15.3 \pm 0.2$ & $2.3 \pm 0.2$ \\
n= 20 & & 35.0 & 7.8 & 2.21 \\
\hline
\end{tabular}

produce planting material for large scale plantations could in future minimize the pressure on wild populations and contribute to the conservation of the valuable medicinal plant.

\section{Acknowledgement}

The author is grateful to the National Science Foundation for financial assistance granted under RG/97/BT/04 and also to Mr. D.J. Naulla and Mr. I. Gunawardene for technical support.

\section{References}

1. Jayaweera D.M.A. (1982). Medicinal Plants Used in Sri Lanka, volume 4, pp. 70 - 71. National Science Council, 47/5, Maitland Place, Colombo.

2. Khan T., Krupadanam D. \& Anwar S.Y. (2008). The role of phytohormone on the production of berberine in the calli cultures of an endangered medicinal plant Coscinium fenestratum. African Journal of Biotechnology 7(18): 3244 - 3246.

3. Murashige T. \& Skoog F. (1962). A revised medium for rapid growth and bioassays with tobacco tissue cultures. Physiologia Plantarum 15:473-497.

4. Wilkinson J. (1986). SYSTAT: The System for Statistics. Systat Inco., Evanston Illinois, USA.

5. Bhojwani S.S. (1980). In vitro propagation of garlic by shoot proliferation. Scientia Horticulturae 13:47-52.

6. Arrilaga M.C.B. \& Segura J. (1987). Somatic embryogenesis from hypocotyl callus culture of Digitalis obscura L. Plant Cell Reports 6:223-226.
7. Balachandran S.M., Bhat S.R. \& Chandel K.P.S. (1990). In vitro clonal multiplication of turmeric (Curcuma spp.) and ginger (Zingiber officinale Rosc.). Plant Cell Reports 8:521-524.

8. Wawrosch C., Malla P.R. \& Kopp B. (2001). Clonal propagation of Lilium nepalense D. Don.-a threatened medicinal plant of Nepal. Plant Cell Reports 20:285288.

9. Senarath W.T.P.S.K., Chandrasena K.G.P.H. \& Fernando K.M.E.P. (2007). In vitro mass propagation and greenhouse establishment of Munronia pinnata (Wall) Theob. (Binkohomba). Journal of the National Science Foundation of Sri Lanka 35(3):181-189.

10. Staritsky G. (1997). Backgrounds and principles of in vitro conservation of plant genetic resources. In: Conservation of plant genetic resources in vitro. (Eds. M.K. Razdan \& E.C. Cocking). pp. 27-52. Science Publisher Inc., New York.

11. Echeverrigaray S., Fracaro F., Andrade L.B., Biasio S. \& Alti-Serafini L. (2000). In vitro shoot regeneration from leaf explant of Roman Chamomile. Plant Cell Tissue Organ Culture 60:1-4.

12. Mandal A.K.A., Chakrabarty D. \& Datta S.K. (2000). Application of in vitro techniques in mutation breeding of Chrysanthemum. Plant Cell Tissue Organ Culture 60:3338.

13. Stefaan P., Werbrouck O. \& Debergh P.C. (1994). Applied aspects of plant regeneration. In: Plant Cell Culture: a practical approach. (Eds. R.A. Dixon \& R.A. Gonzales) pp. 127-145. Oxford University Press, Oxford/, UK.

14. Sairam R.P., Rama G.G. \& Lakshami S.G. (1998). In vitro multiplication of Gymnema sylvestre $\mathrm{R}$. Br. an important medicinal plant. Current Science 75:843-845. 